\title{
A POBREZA FEMININA NOS TERRITÓRIOS DO AGRONEGÓCIO - UM ESTUDO DE CASO DE CRUZ ALTA NO RS ${ }^{1}$
}

\author{
Christiane Senhorinha Soares Campos ${ }^{2}$
}

\section{Resumo}

Esta pesquisa tem como objeto de estudo a relação entre dois processos que se espacializam, simultaneamente, em dezenas de pequenos e médios municípios brasileiros: o aumento da riqueza do agronegócio e da pobreza feminina. Ambos tem seu crescimento estimulado pelas políticas neoliberais, que são implementadas no Brasil a partir da década de 1990. Para atingir verificar a relação entre estes processos, além do levantamento de dados secundários, realizamos um estudo de caso tendo como base a seguinte hipótese: o agronegócio não contribui para reduzir as desigualdades de gênero nos espaços urbanos e rurais em que se territorializa, por promover a exclusão ou a inclusão de forma precária das mulheres no mundo do trabalho. O estudo de caso foi realizado no município de Cruz Alta RS, um dos grandes produtores de soja do estado, e utilizou como principal procedimento metodológico uma pesquisa quantitativa para identificar o perfil do emprego gerado pelos vários segmentos do agronegócio no município. Os resultados validaram a hipótese ao revelar que o perfil hegemônico do emprego gerado pelo agronegócio em Cruz Alta pode ser assim resumido: masculino, formal, temporário e precário.

Palavras-chave: Agronegócio, Pobreza Feminina, Território e Desigualdade de Gênero.

\begin{abstract}
The subject matter of this research is the relation between two processes that materialize themselves simultaneously in the space of small and medium Brazilian municipalities: the increase of wealth of agribusiness and female poverty. The increase of both is stimulated by the neoliberal policies implemented in Brazil since the 1990's. In order to achieve the goal of verifying the relation between agribusiness and female poverty, in addition to gathering secondary data, we undertook a case study having as its basis the following hypothesis: agribusiness does not contribute to the reduction of gender inequalities in urban and rural

\footnotetext{
${ }^{1}$ Este artigo é baseado na tese de doutorado "Pobreza e exclusão feminina nos territórios do agronegócio - o caso de Cruz Alta/RS" defendida pela autora junto ao PPGeografia/UFRGS em 2009 - disponível no endereço eletrônico http://www.lume.ufrgs.br/handle/10183/21080 ou http://hdl.handle.net/10183/21080

${ }^{2}$ Programa de Pós-Graduação em Geografia. Chris_senhorinha@ hotmail.com
} 
spaces in which it territorializes itself because it promotes the exclusion, or the inclusion in precarious ways, of women in the labor market. The case study was undertaken in the municipality of Cruz Alta - RS, one of the major soy producers in the state, and employed as its principal methodological procedure a quantitative research in order to identify the profile of the employment generated by the various segments of agribusiness in the municipality. The results validated the hypothesis in revealing that the hegemonic profile of the employment generated by agribusiness can be summed up accordingly: male, formal, temporary, and precarious.

Keywords: Agribusiness, Female Poverty, Territory, Inequality of gender.

\section{Introdução}

Esta pesquisa evidencia a articulação entre a riqueza do agronegócio e a pobreza e exclusão feminina no interior do Brasil. Estes dois processos se espacializam simultâneamente nos pequenos e médios municípios brasileiros em que a maior parte do capital tem vínculos diretos ou indiretos com o agronegócio, com ênfase para a cadeia produtiva da soja, que é o principal produto agrícola do país em quantidade exportada e em área cultivada.

O processo de integração da agricultura brasileira no mercado mundial intensifica-se a partir da década de 1990 quando um conjunto de reformas de caráter neoliberal começam ser implementadas no país, favorecendo as grandes empresas agroalimentares, particularmente as multinacionais, e dificultando a ampliação e mesmo a reprodução da pequena agricultura. Nesse sentido, no Brasil não há como dissociar a expansão do agronegócio, a ampliação da insersão da agricultura no mercado global, do neoliberalismo.

Partimos do pressuposto de que a tríplice aliança latifúndio-agronegócio-Estado, no contexto neoliberal, é o principal agente responsável pela produção e reprodução da exclusão social e da pobreza no interior do Brasil, na medida em que cria as condições técnicas, políticas e socioeconômicas para a manutenção e/ou intensificação desses processos, cuja forma e conteúdo é ainda mais perverso para as mulheres. Daí a necessidade de fazer o recorte de gênero, sem evidentemente desconsiderar os impactos negativos para o conjunto da população e para os biomas.

A sociedade brasileira está assentada no latifúndio desde o início da colonização portuguesa no século XVI e até hoje ele permanece como um elemento estruturante da formação sócio-econômica e política do país. E é sobre essa arcaica estrutura fundiária que 
vem se desenvolvendo as modernas produções do agronegócio. E o que é pior, em algumas regiões vem se intensificando a concentração da propriedade da terra.

O agronegócio, em nossa compreensão, corresponde à face neoliberal do capitalismo no campo. Isso porque com a implementação das reformas neoliberais no Brasil a partir da década de 1990 a terra se consolida como um espaço de negócio, as atividades agropecuárias se tornam cada vez mais um locus privilegiado de acumulação capitalista e as empresas multinacionais passam a dominar a maior parte das cadeias agroalimentares do país incorporando ou quebrando pequenas e médias empresas, entre as quais muitas cooperativas, que atuavam em escala regional.

Completando a tríplice aliança tem-se o Estado brasileiro, que pode ser caracterizado como "fiel servidor" dos organismos internacionais na implementação das reformas neoliberais que viabilizam, entre outras coisas, o avanço do capitalismo no campo e a inserção do país no mercado agrícola global em condições que comprometem a soberania alimentar. $\mathrm{Na}$ prática, a participação do Estado nessa aliança garantiu a adoção de um conjunto de medidas essenciais para o fortalecimento do agronegócio entre as quais: flexibilização de legislações trabalhistas e ambientais; isenções ou grande redução de impostos para os produtos destinados à exportação, como é o caso da soja, bem como a renegociação de dívidas e concessão de créditos subsidiados para os médios e grandes proprietários rurais. Em nossa concepção essa aliança vem viabilizando a estabilidade e até o aumento da concentração das riquezas nas mãos de uma pequena parcela da população. $\mathrm{O}$ reverso da concentração de riquezas como já se sabe é a produção da pobreza e da exclusão.

Entre os mecanismos de produção da pobreza que se intensificaram na década de 1990 com as reformas neoliberais estão o desemprego e a precarização das condições de trabalho de milhares de pessoas. E essas transformações no mundo do trabalho foram ainda mais negativas para as mulheres, uma vez que elas são maioria entre os desempregados e nos mercados em que se inserem estão nas ocupações mais precárias recebendo os piores salários. Isso faz com que a pobreza no Brasil tenha cada vez mais rosto de mulher.

Por outro lado, o Brasil, sob o comando do presidente Lula, é apontado pelo Banco Mundial como um dos casos de sucesso na implementação de políticas de combate a pobreza, devido ao Bolsa Família - um programa de transferência de renda para famílias pobres, que em 2009 atendia cerca de 11 milhões de famílias brasileiras. Além do foco nos pobres este programa também tem um foco de gênero, uma vez que são as mulheres que recebem o dinheiro. E na seleção das famílias beneficiárias as que são chefiadas por mulheres tem 
prioridade. Dados do Ministério do Desenvolvimento Social - MDS, indicam que em 2005 cerca de $90 \%$ das famílias beneficiadas com o programa eram chefiadas por mulheres.

Não nos parece mera coincidência que as mulheres, que são as mais atingidas pela exclusão social, pobreza e precarização das condições de trabalho no Brasil no contexto neoliberal, sejam o principal alvo das políticas compensatórias no país. Nesta perspectiva, o Estado brasileiro contribui para a retroalimentação da pobreza e da exclusão social no país, na medida em que ao invés de combater contribui para a ampliação da concentração de riquezas e como forma de compensar a população mais afetada intensifica as políticas assistenciais focalizadas, ou focopolíticas (LEGUIZAMÓN, 2005).

No Brasil a maior parte das famílias tem como principal fonte de renda o trabalho, por isso a pobreza no país se intensifica muito com o desemprego e a precarização do mundo do trabalho. E o empobrecimento é ainda mais perverso para as famílias em que a mulher é a única provedora, uma vez que em geral as mulheres têm mais dificuldade de acesso a trabalho, renda e bens devido à enorme desigualdade de gênero vigente na sociedade brasileira.

Nesse sentido, levanta-se a hipótese de que a intensificação da pobreza feminina nos municípios onde a base da economia é o agronegócio decorre da exclusão ou da inclusão precária das mulheres nos processos produtivos vinculados ao agronegócio.

Como este fenômeno está espalhado em todo o território nacional, com múltiplas cadeias produtivas vinculadas a diferentes produtos, para testar essa hipótese definimos como metodologia um estudo de caso no município de Cruz Alta no estado do Rio Grande do Sul, um típico território do agronegócio, onde se realizou uma pesquisa quantitativa para traçar o perfil do emprego gerado pelo agronegócio no âmbito local.

Apesar de focalizada em um pequeno ponto no imenso território brasileiro, a pesquisa empírica, em nossa avaliação, cumpre um papel fundamental de visibilizar a exclusão e a pobreza das mulheres que cresce junto com as supersafras de grãos no interior do Brasil.

\section{Agronegócio em uma perspectiva crítica e multidisciplinar}

No Brasil o significado do termo agronegócio extrapola a tradução literal de agribusiness (inglês) e filière (francês), na medida em que traz em seu cerne um evidente recorte de classe, um modelo de política-econômica para o país e uma estratégia de ocupar e condicionar os usos de espaços cada vez mais amplos em todas as regiões brasileiras. 
Do ponto de vista da divisão de classes sociais, o agronegócio é atrelado às classes dominantes nas diferentes escalas. O caráter elitista do agronegócio brasileiro ganhou visibilidade no processo da Constituinte em que tanto grupos empresariais quanto latifundiários se uniram para inviabilizar a possibilidade de uma reforma agrária ampla e efetiva no país. Mas também se evidencia nos discursos de seus líderes de combate às lutas dos movimentos sociais; nos lobbies para impedir aprovação de leis favoráveis aos trabalhadores como a lei que prevê desapropriação de terras onde for encontrado trabalho escravo; nos lobbies para garantir renegociações de dívidas favoráveis aos grandes proprietários rurais e extremamente prejudiciais aos cofres públicos; na defesa de projetos que beneficiam grandes grupos econômicos em detrimento de populações, como é o caso da transposição do São Francisco no nordeste do país, etc.

As empresas e pessoas físicas vinculadas ao agronegócio são, via de regra, detentoras de propriedades rurais e/ou urbanas, de indústrias, de ações e outras aplicações no mercado financeiro, de múltiplas formas de riqueza, de modo que há uma base material que justifica seu caráter elitista.

Evidentemente que como integrantes das forças políticas dominantes os grupos empresariais e empresários/as do agronegócio produzem discursos que escamoteiam esse caráter de classe, e se apresentam como agentes meramente econômicos, quando na verdade também atuam na esfera política, incidindo sobre as decisões governamentais desde a escala local até a nacional, e produzem ideologia ${ }^{3}$.

No campo ideológico o agronegócio procura difundir a idéia de que é o grande motor da economia brasileira, quando, na verdade, responde por menos de $1 / 3$ do PIB nacional ${ }^{4}$ ainda que em alguns estados e em muitos municípios de fato seja a principal força econômica. E se alardeia que o sucesso do agronegócio é bom para o país, de modo que os interesses dos capitais investidos nos seus diversos ramos de atividade aparecem como sendo interesse nacional. E os setores sociais que se contrapõem ao agronegócio aparecem como sendo inimigos do desenvolvimento sócio-econômico do Brasil. Nesse sentido, a difusão do agronegócio como algo fundamental para o progresso do país tem evidentes interesses de tirar

\footnotetext{
${ }^{3}$ Utiliza-se aqui a definição marxista na qual ideologia está sempre associada ao uso das idéias para dominar, para velar e/ou inverter a realidade (Iasi, 2007).

${ }^{4}$ Conforme Hespanhol (2007) A participação do agronegócio no PIB nacional varia de 27 a $35 \%$, de acordo com os critérios que são empregados para o seu dimensionamento. GUILHOTO et al (2006), analisando a participação do agronegócio no Pib brasileiro entre 1995 e 2003, constata que no ínicio da série temporal o Pib do Agronegócio correspondia a $30,1 \%$ e no final a $30,6 \%$.
} 
da agenda política e social do país outras concepções de agropecuária, como explica Hespanhol (2007).

\begin{abstract}
O termo "agronegócio" passou a ser utilizado de maneira cada vez mais ampla pela mídia e pelas organizações que representam os interesses dos agentes direta e indiretamente vinculados aos complexos agroindustriais do país a partir dos anos 1990, num esforço estratégico para demonstrar a competitividade e a importância do agronegócio, se contrapondo assim, aos interesses dos movimentos sociais que demandam a democratização do aceso a terra por intermédio da reforma agrária.
\end{abstract}

No que tange à política-econômica, o agronegócio defende as propostas neoliberais que resultam na abertura de novos locus de acumulação de capital, como as privatizações e as parcerias público-privadas, bem como a redução do papel do Estado na regulação do mercado de trabalho, no controle de recursos naturais e na garantia de direitos sociais universais, como saúde e previdência. Entretanto, reivindica políticas protecionistas, créditos subsidiados e investimentos estatais para viabilizar maior capacidade produtiva e rentabilidade aos setores do agronegócio. As forças hegemônicas do agronegócio no Brasil defendem que a base da economia do país devem ser a produção e a exportação de commodities. E é nessa perspectiva que intervém nas políticas agrária, agrícola, industrial, ambiental, cambial, tributária e trabalhista no país.

Quanto à dimensão espacial, o agronegócio busca continuamente ampliar seus territórios e, nos espaços apropriados, tem o poder de condicionar a produção e distribuição da maior parte da riqueza, contribuindo também para o seu reverso, a produção da pobreza.

Levando em conta todos esses elementos, é um equívoco considerar qualquer produção agropecuária ou agroindustrial como agronegócio, como tem sido feito aleatoriamente pelos meios de comunicação e por várias instituições públicas e privadas. Em nossa concepção faz parte da estratégia ideológica do capital ,empregado no agronegócio, o uso generalizado desse termo. Com isso, para o senso comum a produção de alimentos vai se tornando sinônimo de agronegócio.

Os agricultores que consomem insumos e máquinas modernos não podem ser confundidos com o agronegócio, caso contrário, todos nós consumidores de mercadorias, seríamos capitalistas. Mesmo unidades agrícolas familiares integradas aos complexos agroindustriais como fornecedoras de matéria-prima não podem ser rotuladas genericamente como representantes do agronegócio. Via de regra, as famílias que trabalham nessas condições têm grande parte de sua renda apropriada pelos setores industriais devido à imposição de preços abaixo do valor e dos elevados custos de produção, como já demonstraram vários autores (OLIVEIRA 1986 e 2002; AMIN e VEGOPOULOS 1986). 
Em nossa concepção, o agronegócio deve ser compreendido como uma complexa articulação de capitais direta e indiretamente vinculados com os processos produtivos agropecuários, que se consolida no contexto neoliberal sob a hegemonia de grupos multinacionais e que, em aliança com o latifúndio e o Estado, tem transformado o interior do Brasil em um locus privilegiado de acumulação capitalista, produzindo, simultaneamente, riqueza para poucos e pobreza para muitos e, por conseguinte, intensificando as múltiplas desigualdades socioespaciais.

Portanto, simplificar o agronegócio como sinônimo de negócios com produtos agropecuários é desconsiderar seu viés elitista, sua dimensão político-ideológica, o modelo de política econômica em que se inser, sua complexa articulação interna e com outros setores da economia e sua capacidade de expansão espacial por meio da construção de territórios, nos quais tem o poder de, entre outras coisas, incluir ou inviabilizar a agropecuária e agroindústria alicerçada no uso da força de trabalho familiar.

Todavia, nos parece necessário entender que agronegócio não pode ser caracterizado apenas como "agricultura capitalista". Trata-se, evidentemente, de uma forma capitalista de produção agrícola, mas que possui características bem demarcadas. Uma dessas características é o fato de que o agronegócio envolve uma ampla articulação de capitais, sob o controle de grupos econômicos multinacionais e cuja maximização de lucros é viabilizada de um lado, por um contexto de globalização neoliberal em que os capitais tem ampla liberdade de circulação, em que ocorre uma rápida difusão de informações, técnicas e tecnologias e, simultaneamente, uma intensa precarização do mundo do trabalho em todos os países capitalistas. Por outro lado, o agronegócio se viabiliza por meio da apropriação de espaços nos Estados para garantir recursos e condições políticas e jurídicas favoráveis às suas atividades.

Nesse sentido, propomos uma perspectiva de análise do agronegócio que tenha um caráter multidisciplinar e leve em conta aspectos político-ideológicos, socioeconômicos e espaciais. E uma abordagem crítica, preocupada em revelar os interesses que estão por traz dos discursos e das ações, compreender as estratégias utilizadas para se consolidar e se expandir territorialmente, além de evidenciar a multidimensionalidade de seus impactos.

\section{Territorialização do Agronegócio}

Um processo de territorialização, à medida que se baseia em uma relação de poder, produz sempre um cenário conflituoso como evidencia Haesbaert (2004:259). 
Se territorializar-se envolve sempre uma relação de poder, ao mesmo tempo concreto e simbólico, e uma relação de poder mediada pelo espaço, ou seja, um controlar o espaço e, através deste controle, um controlar de processos sociais, é evidente que, como toda relação de poder, a territorialização é desigualmente distribuída entre seus sujeitos e/ou classes sociais e, como tal, haverá sempre, lado a lado, ganhadores e perdedores, controladores e controlados, territorializados que desterritorializam por uma reterritorialização sob seu comando e desterritorializados em busca de uma outra reterritorialização, de resistência e, portanto, distinta daquela imposta pelos seus desterritorializadores.

A territorialização do agronegócio, que também é marcada por muitos conflitos, ocorre à medida que segmentos da sua complexa articulação de capitais se apropriam dos espaços. Essa apropriação pode incluir ou não a propriedade de áreas. Como exemplos se pode citar a instalação de segmentos industriais (como agroindústrias, fábricas de fertilizantes e de máquinas agrícolas), de serviços (como empresas de comercialização e armazenamento, de assistência técnica, de transporte, revenda de insumos, crédito, etc), e o setor de produção agropecuária propriamente dita.

É necessário ressaltar que o agronegócio não é apenas uma articulação de capitais, mas também de técnicas, associadas aos processos de trabalho, dos distintos segmentos capitalistas que o compõem. E, como constatou Santos (1998), “as técnicas são solidárias, quando se impõe uma técnica, cria-se a obrigação de trazer outras, sem as quais aquela não funciona bem". Além dessa solidariedade técnica, há uma interdependência entre os capitais, uma articulação sistêmica, de modo que o processo de valorização de um está associado ao desempenho do outro. Esses fatores fazem com que a territorialização do agronegócio ocorra em bloco, um segmento nunca instala de forma isolada.

A moderna "agricultura científica" (SANTOS, 2003), baseada na ciência e na técnica, tem como pré-requisitos o fornecimento do segmento de insumos químicos, máquinas, equipamentos, projetos de irrigação ou drenagem, técnicas de correção de solo, crédito, assistência técnica, entre outros. E após a produção se impõe a necessidade de uma rede de transporte, armazenagem e comercialização, etc. Quanto mais complexo o bloco de capitais, maior a viabilidade econômica do processo de acumulação e maior o poder de apropriação material e simbólica do espaço, transformando-o em território do agronegócio.

Também é necessário entender que para um determinado espaço ser território do agronegócio não basta a presença física de empreendimentos como os que foram citados. Conforme se evidenciou anterioriormente, a construção de território(s) implica, sobretudo, numa relação de poder. Portanto, um determinado espaço torna-se território do agronegócio quando nele os seus segmentos têm o domínio, ou seja, condicionam os usos do espaço; 
utilizam do poder econômico para adequar as decisões políticas a seus interesses; controlam o mercado de trabalho estabelecendo as condições e as remunerações, que servem de referência para outros setores da economia; atraem ou excluem investimentos de outros setores econômicos, enfim detém hegemonia nas defições dos usos no e do espaço.

A territorialização do agronegócio, independente do segmento que serve como carrochefe do processo, é sempre acompanhada de muitos conflitos uma vez que produz impactos no meio ambiente, na economia, na distribuição demográfica, na divisão do trabalho, no jogo de interesses políticos, enfim nas relações sociais com e no espaço. E, conforme afirmamos na introdução as modernas produções do agronegócio no Brasil se desenvolvem sob uma arcaica estrutura fundiária e com o apoio de uma "mão bem visível" do Estado. Portanto, existe no Brasil, e muito provavelmente em outros países latino-americanos, uma tríplice aliança formada pelo agronegócio-latifúndio-Estado, que cria as condições favoráveis para territorialização do agronegócio no contexto de implantação das políticas neoliberais no país, a partir da década de 1990.

A principal contribuição do Estado para a territorialização do agronegócio é por meio de investimentos para equipar o território facilitando os processos de produção e circulação de commodities. Em todas as regiões do país são os investimentos públicos, especialmente do governo federal, que dão suporte à expansão territorial do agronegócio. Nesse caso a palavra suporte tem sentido lato uma vez que é o Estado que realiza as principais obras na infraestrutura de transportes (rodoviário, aeroportuário, ferroviário e portuário), de energia, entre outras que vão moldando os espaços conforme as demandas do capital. Ou seja, o Estado instrumentaliza o território para o consumo do capital. A aliança com o latifúndio ${ }^{5}$ revela que, no seu processo de territorialização, o agronegócio traz elementos novos - nos aspectos técnicos, nas articulações políticas, na articulação de capitais investidos nos negócios de base agropecuária, entre outros - mas, também carrega as heranças da história e da espacialidade do modo capitalista de produção no território brasileiro. Entre essas heranças está a manutenção e até intensificação da concentração fundiária.

Comparando-se dados do último censo agropecuário (o censo 2006), divulgado pelo IBGE em 2009, com os que foram realizados nas décadas de 1990 e 1980 constata-se que nas décadas anteriores o índice de Gini manteve-se praticamente inalterado, e no período mais recente, que coincide com grande expansão do agronegócio, houve aumento deste indicador.

\footnotetext{
${ }^{5}$ Latifúndio é usado nesta tese como sinônimo de grande propriedade fundiária, independente de ser produtivo ou não. Essa ressalva é importante porque alguns autores denominam latifúndio apenas as grandes propriedades improdutivas.
} 
Em 1985 o índice de Gini da área total dos estabelecimentos agropecuários no Brasil era de 0,857; em 1995 o indicador sofre uma pequena redução para 0,856 e em 2006 passou para 0,872, o que indica uma elevação da concentração fundiária (IBGE, 2009).

Outro aspecto que revela a capacidade do agronegócio de unificar barbárie e modernidade (OLIVEIRA, 2003), é o uso de tecnologia de ponta aliado com condições subumanas de trabalho. Um exemplo dessa dualidade é o setor da cana de açúcar em São Paulo, que utiliza colheitadeiras informatizadas e ao mesmo tempo explora até a exaustão a força de trabalho humana, como ocorria nos tempos da escravidão no país.

\begin{abstract}
Nos anos 80, o lavrador fazia cinco toneladas de cana por dia. A mecanização da colheita o obrigou a ser mais produtivo. O corta-cana derruba agora oito toneladas por dia. Para abater toda essa cana, precisa dar 8.000 golpes com seu facão. (...) $\mathrm{O}$ trabalhador deve cortar a cana rente ao chão, encurvado. Usa roupas malajambradas, quentes, que cobrem o corpo, para que não seja lanhado pelas folhas da planta. Mas se acidenta mesmo assim. Se corta com o facão, tem lesões por esforço repetitivo. O excesso de trabalho causa a "birola": tontura, desmaio, cãibra, convulsão. A fim de agüentar dores e cansaço, toma drogas e soluções de glicose, quando não farinha mesmo. Têm havido mais mortes por exaustão nos canaviais. (Jornal Folha de São Paulo, 11/03/2007)
\end{abstract}

E além da intensificação da exploração da força de trabalho, o agronegócio - em consonância com o receituário neoliberal do contexto político-econômico em que se expande no Brasil - promove uma reestruturação no mercado de trabalho dos setores que engloba. Essa reestruturação - ainda que tenha gerado alguns poucos empregos com altos salários para quem detém os conhecimentos técnicos exigidos - para a maioria dos trabalhadores dos territórios do agronegócio ampliou o desemprego e a precarização das condições de trabalho. O resultado foi o aumento da produção da pobreza e da exclusão social nos lugares que se territorializou. E esses processos afetam de forma ainda mais severa as mulheres.

\title{
O (não) lugar da mulher no mundo do agronegócio brasileiro
}

O enxugamento do mercado de trabalho é um eficiente mecanismo de produção e reprodução da pobreza e da exclusão social. E nos municípios em que o agronegócio é a base da economia as mulheres são as maiores vítimas desse processo que se intensificou na década de 1990. Estatísticas do Dieese/Nead(2006:102), revelam que em todo o Brasil as mulheres são as maiores excluídas do mundo do trabalho rural no período de implantação das políticas neoliberais no país, como mostra a Tabela 1. 
Tabela 1 - Variação do pessoal ocupado na agropecuária - Brasil 1993-2004

(em 1.000 pessoas)

\begin{tabular}{l|ccc}
\hline $\begin{array}{l}\text { Pessoal ocupado } \mathbf{n a} \\
\text { agropecuária }\end{array}$ & $\mathbf{1 9 9 3}$ & $\mathbf{2 0 0 4}$ & Variação em \% \\
\hline Homem & $11.930,0$ & $12.063,0$ & 1,1 \\
Mulher & $6.213,2$ & $5.670,9$ & $-8,7$ \\
\hline Total & $18.143,2$ & $17.733,8$ & $-2,3$ \\
\hline Fonte: IBGE.PNAD. Tabulações especiais, Melo, Hildete \& Di Sabbato, Alberto, Elaboração: Dieese, apud PPIGRE/MDA. \\
\multicolumn{4}{l}{ Gênero, agricultura familiar e reforma agrária no Mercosul. }
\end{tabular}

Isso significa que há um recorte de gênero no processo de "enxugamento" do mundo do trabalho rural. Vários estudos, realizados em diferentes regiões do Brasil, analisando distintas produções vinculadas ao agronegócio, evidenciam que a força de trabalho feminina é excluída e/ou incluída de forma precária no mundo do agronegócio.

Rossini (2002:12), ao analisar a condição da força de trabalho feminina empregada no corte da cana de açúcar no estado de São Paulo, constatou uma série de transformações na vida dessas trabalhadoras nas últimas décadas entre as quais: diminuição relativa da mulher na força de trabalho, aumento da participação da mulher na chefia da família e aumento da migração tanto feminina quanto masculina. Verificou também que está havendo um maior controle sobre o corpo feminino, na medida em que os empregadores fazem pressão para que as mulheres realizem laqueaduras (operação que esteriliza as mulheres) ou exigem atestado médico comprovando a não gravidez.

Em estudos sobre os impactos da expansão da fruticultura em municípios do nordeste brasileiro, Cavalcanti et al (2006) constatam a precarização do mercado de trabalho por meio da redução do nível de emprego e da flexibilização das relações trabalhistas com a expansão do trabalho terceirizado, de modo que muitos empregos são oferecidos por empresas especializadas e não pelos produtores.

Segundo os autores também é evidente o predomínio de relações trabalhistas informais e temporárias. No Vale do São Francisco, por exemplo, o Sindicato dos Trabalhadores Rurais de Petrolina (PE) estimava que no início da década de 2000 cerca de 60 mil pessoas trabalhavam em atividades vinculadas a fruticultura na região, mas somente metade tinha carteira assinada, os outros $50 \%$ era informais, não tinham direitos trabalhistas. E do total de trabalhadores apenas 25 mil teriam empregos fixos e 35 mil temporários. (Silva, 2001, apud Cavalcanti et al, 2006:130).

No que se refere à questão de gênero os autores constatam que na maior parte das áreas ocupadas pela fruticultura a força de trabalho feminina é excluída. No Platô de Neópolis, estado de Sergipe, por exemplo, era visível a desigualdade de gênero tanto nos 
empregos permanentes quanto nos temporários. Levantamento feito em junho de 2004 verificou que 811 pessoas trabalhavam nesse segmento do agronegócio no Platô, dessas 611 eram empregadas permanentes - sendo 620 homens e somente 31 mulheres - e 160 eram temporárias - 147 homens e apenas 13 mulheres (Cavalcanti et al, 2006:130). A partir desses dados os autores concluem que:

\begin{abstract}
Enquanto os homens ocupam a quase totalidade dos postos de trabalho, as mulheres se inserem apenas de forma precária e pontual, embora no discurso dos técnicos e gerentes haja o reconhecimento do trabalho feminino como o mais adequado para as tarefas mais leves como adubação e cata às baratas do coqueiro, ambas atividades temporárias. As mulheres são consideradas também mais atenciosas, detalhistas, obdientes e limpas, apesar destas características serem fundamentais para poucas atividades na agricultura do platô.
\end{abstract}

A exclusão feminina do mundo do trabalho rural também foi constatada na região sul do Brasil. Scheneider e Radomsky(2001:4), a partir da análise de dados do IBGE/PNAD ${ }^{6}$, verificam que em números absolutos a redução da população rural não-metropolitana no Rio Grande do Sul, entre 1992 e 1999, foi de aproximadamente 120 mil pessoas. E a principal causa disso foi "desempenho ocupacional declinante" de três setores da agricultura que absorviam força de trabalho familiar: soja, fumo e milho. Sendo a soja a maior responsável pela redução da PEA rural com a expulsão de 127 mil pessoas no período por eles analisado. Conforme os autores, o maior contingente expulso das atividades agrícolas no Rio Grande do Sul nesse período fazia parte da categoria "trabalhadores rurais". Na classificação do IBGE esta categoria é formada pelos membros não remunerados da família, e é aí que se concentra a maior parcela da população rural feminina. Portanto, as mulheres estão entre as mais excluídas das atividades agrícolas no estado.

Esse breve relato da condição feminina nas áreas de cultivo destes três segmentos do agronegócio: cana, frutas e soja, evidencia que independente do tipo de produto a força de trabalho feminina é excluída ou incluída de forma precária nos processos produtivos. Também demonstra que isso não ocorre de forma localizada, uma vez que os estudos são em distintas regiões (sudeste, nordeste e sul) e estados (São Paulo, Sergipe e Rio Grande do Sul) do país.

É comum os especialistas dividirem as atividades do agronegócio em dois grupos, conforme o espaço onde se realizam: 1) da porteira para dentro: que inclui atividades realizadas nas propriedades rurais e engloba todos serviços vinculados à produção agrícola propriamente dita; 2) da porteira para fora: que inclui atividades que estão à montante e à jusante do processo de produção agrícola, ou seja, o que vem antes (insumos e máquinas por

\footnotetext{
${ }^{6}$ IBGE - Instituto Brasileiro de Geografia e Estatística e PNAD - Pesquisa Nacional de Amostra Domiciliar, que é realizada anualmente pelo IBGE em áreas urbanas e rurais.
} 
exemplo) e o que vem depois dessa produção (transporte, armazenagem, agroindustrialização, por exemplo).

Os estudos referidos anteriormente mostram a exclusão feminina ou sua inclusão precária nas atividades dentro da porteira. Mas qual a condição feminina nas demais atividades dos segmentos do agronegócio? Em nossa avaliação compreender o lugar ou não lugar da mulher no mundo do trabalho nos municípios em que o agronegócio dita as regras do jogo econômico é fundamental para entender a produção e a reprodução da pobreza feminina em meio à riqueza desse setor. Por isso o estudo de caso procurou ver a forma de insersão feminina em diferentes espaços do agronegócio.

\section{Estudo de Caso}

O estudo de caso foi a metodologia utilizada nesta pesquisa. Este estudo foi realizado no município Cruz Alta pelos seguintes motivos:

- O município, apesar de ter menos de 70 mil habitantes, conta com uma universidade, sindicatos e movimentos sociais organizados, instituições públicas consolidadas capazes de fornecer informações para a pesquisa;

- Em Cruz Alta estão territorializados múltiplos segmentos do setor do agronegócio possibilitando traçar o perfil dos empregos nos vários segmentos da cadeia produtiva da soja em um único município;

- No município o agronegócio se desenvolve sobre uma estrutura fundiária baseada no latifúndio e com forte apoio governamental tanto em termos de créditos quanto de infraestrutura, entre outros benefícios. Se materializando, portanto, a atuação da tríplice aliança, Agronegócio-latifúndio-Estado;

- Em Cruz Alta se intensificou a exclusão social e pobreza nas últimas décadas, em um contexto de crescimento da riqueza do agronegócio;

- Em Cruz Alta há um elevado percentual de famílias chefiadas por mulheres - cerca de 40\% a maioria delas são pobres e tem domicílio na periferia urbana.

De modo que se configura no município a situação que é o objeto de estudo desta pesquisa: intensificação da pobreza e da exclusão social, particularmente de mulheres, em um contexto de crescimento do agronegócio. Ou seja, se pode visibilizar em Cruz Alta a face feminina da pobreza em meio à riqueza do agronegócio.

Como a noção de território implica sempre uma relação de poder, constatou-se que o poder do agronegócio no município se manifesta em múltiplas dimensões, como por exemplo: 
a) na propriedade do espaço físico, na medida em extensão territorial da área onde se concentram as grandes e médias propriedades com produção nos moldes da agricultura empresarial é maior do que a destinada à agricultura familiar, como mostra o mapa 1

\section{Mapa 1: Cruz Alta - Divisão espacial em urbana e rural e subdivisão da rural em} agricultura familiar, patronal e reserva ambiental.

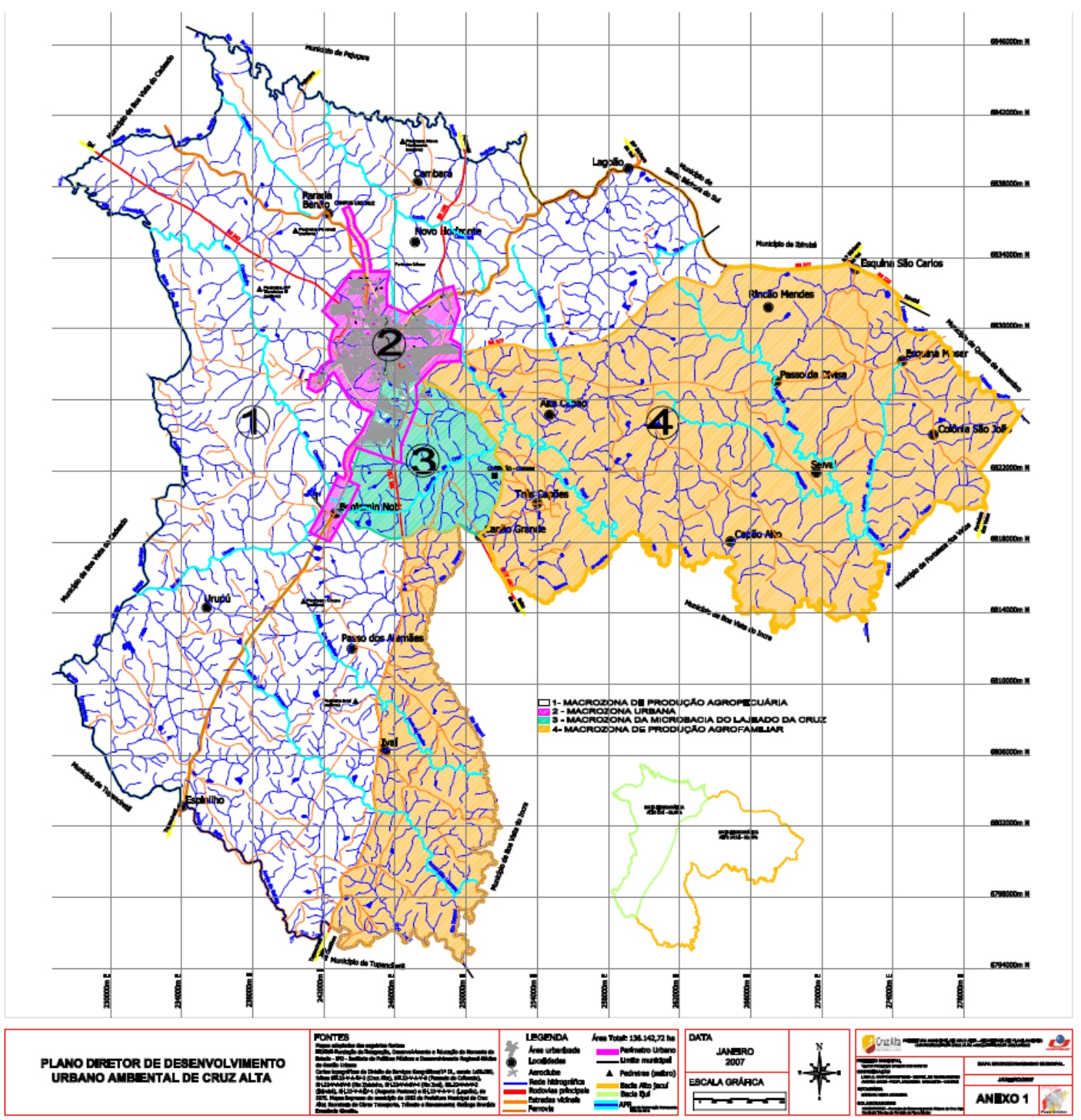

Como se pode ver no mapa, a área 2, que corresponde ao núcleo urbano, ocupa uma pequena extensão territorial, mas concentra mais de $90 \%$ da população do município. Na área 3 se localizam espaços de reserva ambiental e, oficialmente, não pode haver exploração econômica das terras e recursos hídricos. A área 4, em tese é ocupada pela agricultura 
familiar, inclusive conta com um assentamento de reforma agrária. Entretanto, muitas das terras localizadas nesta parte do município, inclusive lotes do assentamento, são arrendadas para médios e grandes produtores de soja. A área 1, que ocupa a maior parte do território municipal, é onde se concentram as médias e grandes propriedades, quase que exclusivamente destinadas à produção de trigo, milho e, principalmente, soja.

b) na padronização da paisagem com o predomínio da monocultura da soja, de modo que pode-se dizer que o agronegócio define o que deve ser produzido mesmo nos espaços em que a propriedade jurídica da terra é de camponeses. Sem contar que no caso do município grande parte das áreas da agricultura familiar, onde em outros tempos predominava a policultura, atualmente são arrendadas pelos capitalistas da soja;

c) na definição de como os produtos devem ser cultivados, garantindo assim mercado consumidor para os segmentos do agronegócio produtores de sementes e outros insumos, máquinas, etc. De modo que os agricultores que cultivam os mesmos produtos de outra maneira (por exemplo, soja não transgênica) têm que arcar com maiores custos, pois não conseguem no âmbito local os insumos e nem armazéns para depositar o produto.

Assim, se observa em Cruz Alta os dois processos analisados por Oliveira (2004), a territorialização do agronegócio e a monopolização do território por este. No primeiro caso os capitalistas desse setor da economia têm o domínio jurídico, econômico e político do espaço. No segundo caso determinam, a partir de vários mecanismos, como deve ser ocupado o espaço, mas sem deter a propriedade.

A maior parte das terras ocupadas com cultivos vinculados às cadeias do agronegócio em Cruz Alta é em grandes e médias propriedades, o que significa que há uma relação bastante estreita entre latifúndio e agronegócio no município. Também se constatou que os proprietários de empreendimentos de diferentes ramos do agronegócio são também proprietários e produtores rurais.

No município estão territorializados vários segmentos da cadeia produtiva da soja, que inclui a produção do grão propriamente dita, o comércio dos equipamentos e insumos usados nas lavouras, os transportes e processo de agroindustrialização, entre outros. E apesar da maioria dos empreendimentos ser de iniciativa privada, é evidente a importância do Estado para garantir o funcionamento de toda a engrenagem do agronegócio local. Entre outras coisas, a mão do Estado é visível no financiamento de lavouras e equipamentos agrícolas, nas 
obras de infra-estrutura rodoviária, nas isenções de impostos para produtos destinados à exportação (lei Kandir).

Em Cruz Alta a atuação da tríplice aliança agronegócio-latifúndio-Estado por um lado gera muita riqueza no município, por outro lado produz e reproduz a pobreza, por meio da concentração de terras, de rendimentos, de outras formas de riqueza, bem como da exclusão ou inclusão precária de trabalhadores, principalmente das mulheres, no mundo do trabalho.

\section{Procedimento metodológico}

O principal procedimento metodológico do estudo de caso foi uma pesquisa quantitativa que consistiu em aplicar questionários com perguntas abertas e fechadas. O público alvo foram empregadores (pessoas físicas e jurídicas) dos diferentes ramos de atividade do agronegócio no município, visando abranger principalmente os vários elos da cadeia produtiva da soja. Conseguiu-se entrevistar entre 60 e $100 \%$ dos empregadores de diferentes ramos do agronegócio com sedes de empresas presentes no perímetro urbano municipal e uma representação simbólica de empregadores proprietários rurais.

No total foram aplicados questionários a 31 empregadores que juntos geravam no período do levantamento de dados 3.099 empregos, sendo 97\% formais (3.019 em números absolutos de ocupações formais). Conforme dados do Ministério do Trabalho ${ }^{7}$ em Cruz Alta foram gerados 10.797 empregos formais no ano de 2008. Portanto, a pesquisa abrangeu empregadores responsáveis por $28 \%$ dos empregos gerados no município no ano pesquisado, o que representa uma amostra bastante significativa. Os empregadores entrevistados foram:

- Empresas de comercialização de máquinas/implementos e produtos agrícolas - nove questionários, abrangendo $60 \%$ dos estabelecimentos deste tipo no município;

- Empresas de produção/armazenamento e comercialização de grãos (incluindo sementes) cinco questionários; Foram entrevistados $60 \%$ dos empregadores que geram mais de 10 empregos.

- Empresas de armazenamento/comercialização e indústria de grãos - 10 questionários atingindo $80 \%$ dos empregadores;

- Empresas de Transporte Ferroviário - um questionário, atingindo 100\% dos empregadores uma vez que só uma empresa deste tipo em Cruz Alta;

- Empresa de contratação de trabalhadores rurais - um questionário, atingindo $100 \%$ dos empregadores, pois só há uma empresa desse tipo no município.

\footnotetext{
${ }^{7}$ Os dados de empregos formais do Ministério do Trabalho do Brasil podem ser acessados no seguinte endereço eletrônico: www.mte.gov.br/pdet/consultas/isper
} 
- Proprietários/as rurais - cinco questionários (sendo dois homens e três mulheres) - uma representação simbólica desse tipo de empregadores.

\section{O perfil do emprego gerado pelo agronegócio de Cruz Alta}

Os resultados da pesquisa quantitativa nos permitem resumir o perfil do emprego gerado pelo agronegócio em Cruz Alta em quatro palavras: masculino, formal, temporário e precário. É masculino porque dos 3.099 postos de trabalho gerados pelos 31 empregadores pesquisados, apenas 694 (em torno de $22 \%$ do total) são ocupados por mulheres. É formal porque $97 \%$ dos empregos tinham contrato de trabalho que garante direitos trabalhistas. É temporário porque $66 \%$ dos empregos são oferecidos por um período pré-determinado, geralmente de três meses. E a precarização se manifesta nos baixos salários, nas restritas oportunidades de ascensão profissional e principalmente na temporalidade dos empregos. A exclusão ou inclusão precária das mulheres pôde ser verificada pelos seguintes aspectos:

- elas ocupam menos postos de trabalho tanto nos empregos fixos (somente 18\% do total) quanto nos temporários (25\%). A justificativa dos empregadores é que se tratam de serviço pesado, entretanto mesmo os cargos de vendedores, gerentes, entre outros que não exigem força muscular são ocupados por homens em quase todos os locais pesquisados;

- do total de postos de trabalho preenchidos por mulheres $73 \%$ são temporários, sendo somente $27 \%$ fixos (187 postos). Os empregos temporários femininos são basicamente para o trabalho em propriedades rurais e o vínculo empregatício é com uma empresa terceirizada e não com o proprietário da fazenda. Os empregos fixos femininos são, em quase sua totalidade, urbanos e a maioria em atividades comerciais, administrativas e de serviços de limpeza;

- há uma desigualdade salarial entre homens e mulheres, pois na maioria dos locais pesquisados a média salarial feminina fica abaixo da masculina. Nos locais pesquisados, a maior parte dos homens recebe entre dois e cinco salários mínimos. E a menor remuneração varia de um a dois salários mínimos. Em três estabelecimentos, a remuneração masculina varia de cinco a dez salários mínimos. No caso das mulheres, a maioria dos estabelecimentos paga entre um e dois salários mínimos. Há inclusive duas empresas em que o salário das trabalhadoras não chega ao mínimo nacional.

No Brasil vários estudos apontam que os trabalhadores com maiores rendimentos são os que tem maior nível educacional. Entretanto, no mercado de trabalho vinculado ao agronegócio em Cruz Alta a maior escolaridade feminina não se traduz em melhores salários, pois como se constatou a média salarial feminina é menor que a masculina e elas tem mais anos de estudo. Nos locais pesquisados, $58 \%$ dos homens empregados possuem até o ensino 
fundamental completo e $42 \%$ têm até o ensino médio ou ensino superior. Entre as mulheres trabalhadoras a situação se inverte, quase $70 \%$ têm ensino médio ou superior e $29 \%$ tem apenas o ensino fundamental.

Em síntese, o que se percebe no mercado de trabalho vinculado ao agronegócio em Cruz Alta é que a quantidade de empregos que gera é desproporcional ao poder econômico das empresas e proprietários rurais. Isso porque são as atividades deste setor que concentram a maior parte das riquezas do município (terras, industrias, casas comerciais, entre outras), entretanto, geram poucos empregos diretos. Além disso, este mercado de trabalho se caracteriza pela precarização, na medida em que predominam os empregos temporários e com baixos salários.

E para as mulheres a situação é ainda pior. A pesquisa constatou que independente de sua escolaridade, elas têm menos acesso aos postos de trabalho por sua condição de gênero. Nos cargos de menor poder de decisão e pequena remuneração a pouca participação feminina é justificada por ser trabalho pesado. Mas a participação delas é ainda menor nos cargos de maior poder de decisão e melhores remunerações, que de modo algum requerem a força física alegada pelos empregadores.

\section{Conclusões}

No estudo de caso, se evidenciou que a pobreza em Cruz Alta tem rosto de mulher. E o agronegócio contribui decisivamente para retroalimentar a probreza, pois suas atividades movimentam a economia local, mas geram poucos e precários empregos, principalmente para a população feminina.

A pesquisa quantitativa constatou que há uma evidente assimetria de gênero no preenchimento das vagas de empregos geradas pelo agronegócio, se privilegia os homens em detrimento das mulheres. Também se verificou uma segregação ocupacional por gênero que reserva aos homens tanto os postos que exigem trabalho operacional quanto de gestão e direção, ficando as mulheres segregadas em funções burocráticas sem poder decisório ou em atividades que o senso comum define como femininas, como os serviços de limpeza e cozinheira.

Essa situação de exclusão ou de inclusão precária da força de trabalho feminina nos territórios do agronegócio também foi constatada em estudos desenvolvidos em outros estados em áreas com predomínio de outros produtos agrícolas (ROSSINI, 2002; CAVALCANTI et al, 2006). Desse modo, podemos inferir que onde se territorializa o agronegócio se intensifica a desigualdade de gênero no mundo do trabalho, o que, por sua vez, contribui para 
retroalimentar a produção da pobreza especialmente nas famílias em que a mulher é a única provedora, como é o caso de muitas famílias pobres da periferia urbana de Cruz Alta.

Em síntese, esta pesquisa contribui para visibilizar a pobreza feminina que cresce simultâneamente à expansão da territorialização do agronegócio no interior do Brasil, uma vez que as mulheres são excluídas da maior parte dos postos de trabalho gerados pelo setor e nos locais em que se inserem se concentram nas ocupações mais precárias.

\section{Bibliografia}

AMIN, S. ; VEGOPOULOS, K. A questão agrária e o capitalismo, Rio de Janeiro, Paz e Terra, 1986.

CAMPOS, C. Pobreza e exclusão feminina nos territórios do agronegócio - o caso de Cruz Alta/RS, tese, PPPGea/UFRGS, Porto Alegre, 2009.

CAVALCANTI, J.; MOTA, D.; SILVA, P. "Transformações recentes nos espaços de fruticultura do nordeste do Brasil", in, ELIAS, D. e PEQUEÑO, R. (org.), Difusão do Agronegócio e novas dinâmicas socioespaciais, Fortaleza, Banco do Nordeste, 2006.

DIEESE/NEAD, Estatísticas do meio rural 2006, São Paulo, MDA, 2006.

Estatísticas do meio rural 2008, São Paulo, MDA, 2008.

GONÇALVES, C.“Geografia da riqueza, fome e meio ambiente - pequena contribuição crítica ao atual modelo agrário/agrícola de uso dos recursos naturais". In OLIVEIRA, A. e MARQUES, M. (org), O campo no século XXI - território de vida, de luta e de construção da justiça social, São Paulo, Casa Amarela e Editora Paz e Terra, 2004.

HAESBAERT, R. O mito da desterritorialização: do fim dos territórios à multiterritorialidade. Rio de Janeiro, Bertrand Brasil, 2004.

HESPANHOL, A. Origem, magnitude e expansão territorial do agronegócio no Brasil, III Encontro de Grupos de Pesquisa Rurais, Porto Alegre, 2007 (no prelo).

IASI, M. Ideologia ... quer uma para viver?, em Ensaios sobre consciência e emancipação, São Paulo, Expressão Popular, 2007.

IBGE, Censo Agropecuário 2006, Brasília, 2009. Disponível em http://www.ibge.gov.br/home/estatistica/economia/agropecuaria/censoagro/default.shtm

LEGUIZAMÓN, S. Trabajo y producción de la pobreza em Latinoamérica y El Caribe estructuras, discursos y actores, Buenos Aires, Clacso Libros (colección Clacso-Crop), 2005. 
OLIVEIRA, Ariovaldo Umbelino, A apropriação da renda da terra pelo capital na citricultura paulista, Terra Livre 01, ano 1, São Paulo, AGB, 1986.

A. Barbárie e modernidade: as transformações no campo e o agronegócio no Brasil. Revista Terra Livre, São Paulo, ano 19, v. 2, n. 2, jul/dez, 2003.

Geografia agrária: perspectivas no início do século XXI, in OLIVEIRA, A. e MARQUES, M. (org.), O campo no século XXI - território de vida, de luta e de construção da justiça social, São Paulo, Casa Amarela e Paz e Terra, 2004.

ROSSINI, R. A modernidade tecnológica no campo exclui a mulher e acelera as masculinidades na agricultura, anais do XIII Encontro da Associação Brasileira de Estudos Populacionais, Ouro Preto/MG, novembro de 2002.

SANTOS, M. Da política dos Estados a política das empresas, Caderno Escola Legislativo, Belo Horizonte, jan/junho, $1998 . \quad$ (disponível em http://www.almg.gov.br/CadernosEscol/Caderno6/santos.pdf )

Por uma outra globalização - do pensamento único à consciência universal, décima edição, Rio de Janeiro/São Paulo, Record, 2003.

SCHNEIDER, S.;RADOMSKY, G. O mercado de trabalho rural gaúcho na década de 1990: as transformações recentes, anais do XXXIX Congresso da Sociedade Brasileira de Economia e Sociologia Rural, Recife, 5-8/08/2001, disponível no endereço www.eco.unicamp.br/nea/rurbano/textos/congrsem/sober01/s01sergi.html. 